\title{
Interleukin-6 is a better metabolic biomarker than interleukin-18 in young healthy adults
}

\author{
Júlia Cristina Cardoso Carraro - Helen Hermana M. Hermsdorff • \\ Blanca Puchau • M. Ángeles Zulet • Fermín I. Milagro • \\ Josefina Bressan • J. Alfredo Martínez
}

Received: 22 October 2014 / Accepted: 5 February 2015 /Published online: 27 February 2015

(C) University of Navarra 2015

\section{Introduction}

Inflammation is a physiological defense response to injury and foreign substances, in order to maintain body homeostasis [27]. However, it can also be triggered by disorders, such as obesity or diabetes, in metabolically active tissues [4].

Obesity and excessive body fat content are associated with increased circulating levels of proinflammatory cytokines [47, 18], supporting a link between chronic low-grade inflammation and diseases such as diabetes and insulin resistance [41], dyslipidemia [18], and, consequently, metabolic syndrome (MetS) features [36]. In addition, previous studies have reported that weight loss leads to a reduction of these proinflammatory molecules [17], making the cytokines an interesting biomarker to follow changes associated to cardiometabolic risk and obesity management. On the other hand, it has been postulated that inflammation could trigger obesity

J. C. C. Carraro · H. H. M. Hermsdorff · J. Bressan Department of Nutrition and Health, Universidade Federal de Viçosa, Viçosa, Minas Gerais, Brazil

B. Puchau • M. Á. Zulet · F. I. Milagro · J. A. Martínez ( $\square)$ Department of Nutrition, Food Science and Physiology, Centre for Nutrition Research, University of Navarra, C/ Irunlarrea 1, 31008 Pamplona, Navarra, Spain e-mail: jalfmtz@unav.es

M. Á. Zulet · F. I. Milagro · J. A. Martínez CIBERobn, Centro de Investigación Biomédica en Red-Fisiopatología de la Obesidad y la Nutrición, Carlos III Institute of Health, Madrid, Spain
[28]. Thaler and Schwartz (2010) proposed that inflammation in hypothalamic cells, caused by excess of nutrients (mainly fatty acids), can promote resistance to insulin or leptin actions, driving to excessive weight gain [38].

Therefore, the identification of early biomarkers to metabolic disturbances with diagnostic value, including inflammatory markers, in order to prevent future damages and facilitate early treatments is still a great challenge, mainly in young subjects.

In this context, interleukin 6 (IL-6) is a proinflammatory cytokine whose levels have been reported to increase in proportion to the degree of obesity, particularly central adiposity, and to insulin resistance [23]. The levels of IL- 6 are often increased in obese subjects, both in adipose tissue and in the blood [11], decreasing in patients undergoing exercise and after caloric restriction [13]. IL-6 levels have been associated with the percentage of total body fat, waist circumference (WC), waisthip ratio (WHR), and total cholesterol:HDL ratio (TC:HDL ratio), [18] as well as the development of chronic disorders, such as cardiovascular diseases [44].

Another cytokine associated with obesity is interleukin 18 (IL-18). IL-18 is produced by macrophages and Kupffer cells, and was first described as an interferon- $\gamma-$ inducer factor (IGIF) in T and natural killer cells from mice infected with Propionibacterium acnes [10]. The secondary structure of IL-18 in the form of $\beta$-sheet folded makes it more closely related to IL- $1 \beta$ than any other cytokine [10]. Increased levels of this cytokine have been related to obesity, type 2 diabetes [45], insulin resistance [1], and atherogenesis [12]. 
In turn, it is recognized that lifestyle factors, such as dietary pattern, physical activity, and smoking, can interfere with inflammatory marker concentrations [24, $16,21,14]$. However, little is known about the relationships between inflammatory markers and metabolic traits in young healthy subjects.

The hypothesis of the present study is that subtle changes may occur in healthy people long time before the onset of the disorders, and may increase the risk to develop metabolic complications. Therefore, we aimed to assess the potential value of IL- 6 and IL-18 as early biomarkers of metabolic disorders, as well as to identify the determinants of variation in the concentrations of these cytokines in young healthy adults, with emphasis in metabolic and lifestyle variables.

\section{Materials and methods}

Subjects

In this study, 153 apparently healthy young adults (50 males, 103 females), with a mean age of $21 \pm 3$ (range: 18-34 years old) and a mean body mass index (BMI) of $22.1 \pm 2.5$ (range $17.4-29.3 \mathrm{~kg} / \mathrm{m}^{2}$ ), were recruited through magazines, radio, web page, and intranet tools from the Universities of Navarra (UNAV) and Public of Navarra (UPNA). In the recruitment message, the age range (18-35 years old) was mentioned, as well as relevant clinical information for those interested in participating in this nutritional survey. The enrollment questionnaire was devised to assess the nutritional status and to provide appropriate dietary advises to the participants. In addition, a phone number and an e-mail address were provided for a continuous contact. Exclusion criteria included pregnancy, inflammatory, heart and respiratory diseases, hormonal treatments, or prescribed drugs that could affect glucose metabolism, alcohol and drug dependence, recent follow-up of diets designed to weight loss, or unstable weight in the last 3 months. These exclusion criteria were screened firstly by phone, and those that passed this step were further screened by a questionnaire fulfilled by a trained physician. Each volunteer signed a written informed consent, which was previously approved by the Investigation Ethics Committee of the Clínica Universidad de Navarra (ref number 79/2005), in accordance with the principles of the Helsinki Declaration.
Anthropometry and body fat distribution

Anthropometric determinations, such as weight, height, waist and hip circumferences, and skinfold thickness, as well as calculated indexes, were taken using standard measurement procedures [20]. BMI $\left(\mathrm{kg} / \mathrm{m}^{2}\right)$ and total $\mathrm{BF}(\%)$ were used as indicators of total adiposity, while measurements of WC $(\mathrm{cm})$ and WHR were used as indicators of central fat accumulation [20].

Blood pressure and biochemical assessments

Systolic (SBP) and diastolic blood pressures (DBP) were measured following World Health Organization guidelines [42]. Venous blood samples were drawn after a $12 \mathrm{~h}$ overnight fast by venipuncture. The EDTAplasma and serum samples were obtained by centrifugation $\left(3500 \mathrm{rpm} \times 15 \mathrm{~min}\right.$ at $\left.4{ }^{\circ} \mathrm{C}\right)$, and frozen immediately at $-80{ }^{\circ} \mathrm{C}$ until assay. Serum concentrations of triglycerides, total cholesterol (TC), high-density lipoprotein-cholesterol (HDL-c), Complement C3 (C3), and glucose and insulin were measured by standard methods as previously described [18]. Insulin resistance was calculated as homeostasis model assessment-estimated insulin (HOMA-IR) according to Matthews et al. [25]. Another index used to estimate insulin resistance was the triglyceride-glucose index (TyG), calculated according to Simental-Mendía et al. [37]. Plasma circulating concentrations of C-reactive protein (CRP, Immundiagnostik AG, Bensheim, Germany), highsensitivity IL-6 (hs-IL-6; R\&D Systems, Minneapolis, MN, USA), high-sensitivity tumor necrosis factor-alpha (hs-TNF- $\alpha$; R\&D Systems, Minneapolis, MN, USA), and IL-18 (Medical \& Biological Laboratories Co., Naka-ku Nagoya, Japan) were evaluated by specific commercial enzyme-linked immunosorbent assay procedures in an automated analyzer system (Triturus, Grifols, Barcelona, Spain) as described by the manufacturer. In our laboratory, the inter- and intra-assay coefficients of variability were $<10 \%$.

\section{Lifestyle features}

The participants were asked about smoking status (never, former, or current smokers), smoking time in lifecourse, and number of cigarettes per day. With respect to physical activity, the participants informed whether they performed regular physical activity (yes/no), and if so, the type and the physical activity (h/week) [16]. To 
quantify the volume of activity, a metabolic equivalent index was also computed by assigning a multiple of resting metabolic rate to each activity [8].

\section{Statistical analyses}

Results are reported as mean \pm SEM and variable distribution was determined by the Shapiro-Wilk test. In order to analyze anthropometric, biochemical, inflammatory, and dietary pattern and lifestyle characteristics with respect to IL-6 and IL-18 concentrations, these cytokines were taken as suitable variables considering their medians as cutoff values $(1.07 \mathrm{pg} / \mathrm{mL}$ and $180.0 \mathrm{ng} / \mu \mathrm{L}$, respectively). Statistical comparisons between groups were performed by the parametric Student $t$ test, Mann-Whitney $U$ test, or $\chi^{2}$ test, as appropriate. In order to analyze inflammatory marker concentrations with respect to anthropometrical and metabolic data of the study participants, BMI, WC, WHR, HOMA-IR, and TyG index were distributed into tertiles in order to assess trends. Finally, multiple linear regression models were performed to analyze the prediction of plasma IL-6 and IL-18 concentrations (outcome) for selected variables and using both cytokines as predictors of metabolic and inflammatory traits related to the MetS. Nonnormally distributed variables were log-transformed prior to inclusion in linear regression analyses. Statistical analyses were performed with SPSS 15.0 software (SPSS Inc., Chicago, IL, USA). A $P$ value $<0.05$ was considered as statistically significant.

\section{Results}

Anthropometric, metabolic, inflammatory, and lifestyle characteristics are described according to the medians of IL-6 and IL-18 (Tables 1 and 2). Gender distribution (data not shown) and age did not differ between the lower and higher IL-6 or IL-18 groups. Individuals with higher concentrations of IL-6 had higher values of BMI, WC, WHR, body fat percentage, and plasma CRP concentration, as well as higher TyG index. Those subjects with higher concentrations of IL-18, in turn, showed an increased TC:HDL ratio (Table 1).

When evaluated by lifestyle, individuals with higher concentrations of both cytokines showed higher frequency of smoking or higher daily number of cigarettes (Table 2). No significant differences were found with regard to physical activity between groups (Table 2). IL-
6, but not IL-18, showed a trend to increase with the rise of WC and TyG index (Fig. 1).

When using multiple linear regression models to analyze the factors that contribute to the variations in the studied interleukins (Table 3), age, BMI, glucose, triglycerides, C3, CRP, number of cigarettes smoked per day, and physical activity level contributed with approximately $24 \%$ to IL-6 variation. Age, BMI, triglycerides, glucose, and CRP were independent predictors $(P<0.005)$. In turn, BMI, total cholesterol, triglyceride, C3, HOMA-IR, and number of cigarettes smoked per day contributed to a variation of $19 \%$ in plasma IL-18. BMI, C3, HOMA-IR and smoking habits were independent predictors $(P<0.005)$.

Furthermore, IL-6 was able to predict the concentrations of TyG index, CRP, Total cholesterol and C3. However, once have been found that IL-6 levels are correlated to number of cigarettes smoked per day, the regressions were adjusted by number of cigarettes and others confounding variables. The relationship between IL-6 levels and TyG index and CRP remained significant even after adjustment for age and BMI and number of cigarettes smoked per day (p adjusted) as shown in Fig. 2. IL-18 predicted HOMA-IR and insulin and triglyceride concentrations, even after the adjustments (data not shown), but this influence was very poor in relation to the biological effects. All models were also further adjusted by sex, daily energy intake, and physical activity level (metabolic equivalents/day) without changing the associations (data not shown).

\section{Discussion}

Inflammation appears to be a defense metabolic process that links obesity onset and the development of MetS features [47]. Inflammatory biomarker concentrations, such as those of CRP, TNF- $\alpha$, IL-6, and IL-18, are often elevated in obese individuals, and associated to higher cardiovascular risks and insulin resistance [1,2].

The expansion of adipose tissue promotes the recruitment of immune cells, enhancing the production of proinflammatory cytokines, as well as the density of macrophages in visceral adipose tissue [39]. Furthermore, hypoxia, promoted by the expansion of adipose tissue, leads to increased production of these cytokines in order to trigger angiogenesis and improve the blood flow to the tissue [34]. However, the increase in the 
Table 1 Anthropometric and clinical characteristics of the participants $(n=153)$, according to the median of plasma IL-6 $(1.07 \mathrm{pg} / \mathrm{mL})$ and IL-18 (180.0 ng/ $\mu \mathrm{L})$ concentrations

\begin{tabular}{|c|c|c|c|c|c|c|c|}
\hline Descriptive means & $\begin{array}{l}\text { All } \\
(n=153)\end{array}$ & $\begin{array}{l}\text { Lower IL-6 } \\
(n=76)\end{array}$ & $\begin{array}{l}\text { Higher IL-6 } \\
(n=77)\end{array}$ & $P$ value & $\begin{array}{l}\text { Lower IL-18 } \\
(n=76)\end{array}$ & $\begin{array}{l}\text { Higher IL-18 } \\
(n=77)\end{array}$ & $P$ value \\
\hline Age (years) & $20.8 \pm 0.2$ & $20.7 \pm 0.2$ & $20.9 \pm 0.3$ & 0.572 & $21.0 \pm 0.3$ & $21.0 \pm 0.3$ & 0.614 \\
\hline BMI $\left(\mathrm{kg} / \mathrm{m}^{2}\right)$ & $22.0 \pm 0.2$ & $21.4 \pm 0.2$ & $22.7 \pm 0.3$ & 0.001 & $21.9 \pm 0.3$ & $22.2 \pm 0.3$ & 0.622 \\
\hline $\mathrm{WC}(\mathrm{cm})$ & $72.7 \pm 0.6$ & $70.7 \pm 0.7$ & $74.8 \pm 0.9$ & 0.001 & $72.8 \pm 0.9$ & $72.7 \pm 0.8$ & 0.957 \\
\hline WHR & $0.74 \pm 0.00$ & $0.73 \pm 0.00$ & $0.75 \pm 0.01$ & 0.024 & $0.742 \pm 0.01$ & $0.741 \pm 0.00$ & 0.912 \\
\hline Body fat (\%) & $20.0 \pm 0.5$ & $18.8 \pm 0.7$ & $21.2 \pm 0.8$ & 0.002 & $19.6 \pm 0.8$ & $20.4 \pm 0.7$ & 0.956 \\
\hline Systolic BP (mmHg) & $114.9 \pm 0.9$ & $114.3 \pm 1.4$ & $115.6 \pm 1.2$ & 0.481 & $116 \pm 1$ & $114 \pm 1$ & 0.439 \\
\hline Diastolic BP (mmHg) & $65.2 \pm 0.6$ & $64.5 \pm 0.9$ & $65.6 \pm 0.9$ & 0.335 & $66 \pm 1$ & $64 \pm 1$ & 0.204 \\
\hline Glucose (mg/dL) & $85.1 \pm 0.6$ & $84.3 \pm 0.8$ & $85.9 \pm 0.9$ & 0.181 & $84.2 \pm 0.8$ & $86.0 \pm 0.9$ & 0.138 \\
\hline Insulin $(\mu \mathrm{U} / \mathrm{L})$ & $7.9 \pm 0.3$ & $7.7 \pm 0.4$ & $8.1 \pm 0.4$ & 0.516 & $7.7 \pm 0.3$ & $8.1 \pm 0.42$ & 0.515 \\
\hline HOMA-IR & $1.7 \pm 0.0$ & $1.6 \pm 0.1$ & $1.7 \pm 0.1$ & 0.376 & $1.6 \pm 0.1$ & $1.7 \pm 0.1$ & 0.354 \\
\hline TyG index & $8.0 \pm 0.0$ & $7.99 \pm 0.2$ & $8.06 \pm 0.2$ & 0.004 & $8.02 \pm 0.2$ & $8.04 \pm 0.2$ & 0.438 \\
\hline Total cholesterol (mg/dL) & $174.8 \pm 2.2$ & $176.1 \pm 3.2$ & $173.5 \pm 3.1$ & 0.566 & $172.1 \pm 3.2$ & $177.5 \pm 3.1$ & 0.228 \\
\hline HDL-c (mg/dL) & $59.8 \pm 1.0$ & $60.3 \pm 1.5$ & $59.2 \pm 1.4$ & 0.605 & $61.4 \pm 1.4$ & $58.1 \pm 13.0$ & 0.111 \\
\hline TC: HDL-c & $3.0 \pm 0.1$ & $3.0 \pm 0.1$ & $3.0 \pm 0.1$ & 0.948 & $2.9 \pm 0.1$ & $3.2 \pm 1.5$ & 0.008 \\
\hline Triglycerides (mg/dL) & $67.9 \pm 2.1$ & $70.3 \pm 3.3$ & $65.6 \pm 2.6$ & 0.267 & $64.0 \pm 2.8$ & $71.9 \pm 3.2$ & 0.066 \\
\hline Complement C3 (g/L) & $1.1 \pm 0.0$ & $1.0 \pm 0.0$ & $1.1 \pm 0.0$ & 0.082 & $1.1 \pm 0.2$ & $1.1 \pm 0.2$ & 0.179 \\
\hline CRP (mg/L) & $1.1 \pm 0.1$ & $0.9 \pm 0.1$ & $1.3 \pm 0.1$ & $<0.001$ & $1.1 \pm 0.1$ & $1.1 \pm 0.1$ & 0.621 \\
\hline $\mathrm{TNF} \alpha(\mathrm{pg} / \mathrm{mL})$ & $2.1 \pm 0.2$ & $1.9 \pm 0.2$ & $2.3 \pm 0.3$ & 0.190 & $2.0 \pm 0.3$ & $2.2 \pm 0.2$ & 0.657 \\
\hline IL-6 (pg/mL) & $1.2 \pm 0.1$ & $0.75 \pm 0.0$ & $1.8 \pm 0.1$ & N/A & $1.2 \pm 0.1$ & $1.3 \pm 0.1$ & 0.573 \\
\hline IL-18 (ng/ $\mu \mathrm{L})$ & $484.1 \pm 65.2$ & $563.6 \pm 99.5$ & $403.6 \pm 83.7$ & 0.220 & $130.2 \pm 3.8$ & $833.4 \pm 116.8$ & N/A \\
\hline
\end{tabular}

$P$ value from Student $t$ test or Mann-Whitney $U$ test (to non-normally distributed variables), when groups were compared

Data are mean \pm SEM

$B P$ blood pressure, $C R P$ C-reactive protein, HOMA-IR insulin resistance index, $H D L-c$ high-density lipoprotein-cholesterol, $T C$ total cholesterol, N/A not available

In italics are $p$ values $<0.05$

circulating levels of these cytokines interferes with the insulin signaling pathway, leading to resistance to the action of this hormone in target tissues [47].
IL-6 is a cytokine produced by many cell types and elicit paracrine, autocrine, and endocrine effects, acting as a mediator of the acute response and determining the

Table 2 Lifestyle features of the participants ( $n=153)$, according to the medians of plasma IL-6 (1.07 pg/mL) and IL-18 (180.0 ng/ $\mu \mathrm{L})$ concentrations

\begin{tabular}{|c|c|c|c|c|c|c|c|}
\hline Characteristics & $\begin{array}{l}\text { All } \\
(n=153)\end{array}$ & $\begin{array}{l}\text { Lower IL-6 } \\
(n=77)\end{array}$ & $\begin{array}{l}\text { Higher IL-6 } \\
(n=76)\end{array}$ & $P$ value & $\begin{array}{l}\text { Lower IL-18 } \\
(n=76)\end{array}$ & $\begin{array}{l}\text { Higher IL-18 } \\
(n=77)\end{array}$ & $P$ value \\
\hline Self-reported physical active practice (yes) & $82(53.6)$ & $38(46.3)$ & $44(53.7)$ & 0.289 & $41(50)$ & $41(50)$ & 0.930 \\
\hline Metabolic equivalents (h/week) & $37.6 \pm 2.3$ & $41.5 \pm 3.4$ & $36.6 \pm 3.0$ & 0.213 & $39.8 \pm 3.3$ & $35.4 \pm 3.2$ & 0.188 \\
\hline Smokers (yes) & $50(32.7)$ & $23(46)$ & $27(54)$ & 0.556 & $19(38)$ & $31(62)$ & 0.044 \\
\hline Smoking time (years) & $1.3 \pm 0.2$ & $1.2 \pm 0.3$ & $1.4 \pm 0.2$ & 0.497 & $0.8 \pm 0.2$ & $1.8 \pm 0.3$ & 0.019 \\
\hline Cigarettes (n/day) & $2.5 \pm 0.4$ & $1.9 \pm 0.5$ & $3.2 \pm 0.6$ & 0.003 & $1.6 \pm 0.5$ & $3.5 \pm 0.7$ & 0.021 \\
\hline
\end{tabular}

$P$ values from Mann-Whitney $U$ test to continuous variables and $\chi^{2}$ test to dichotomy variables, when groups were compared Data are mean \pm SEM or $\mathrm{n}$ (frequency in percents) to continuous or dichotomy variables In italics are $p$ values $<0.05$ 

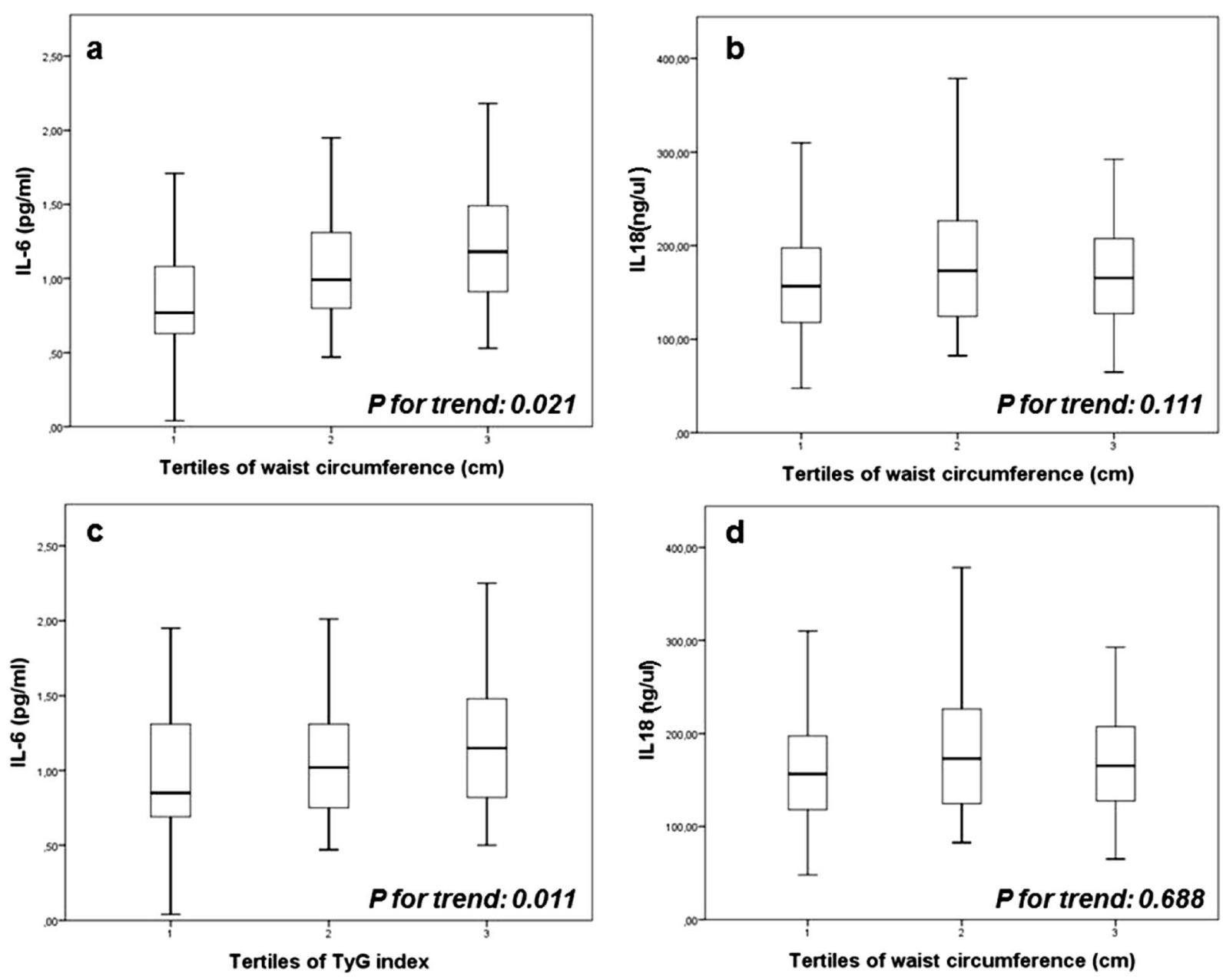

Fig. 1 Plasma IL-6 (a) and IL-18 (b) concentrations $(n=153)$, according to the distribution of waist circumference (centimeters) into tertiles, and IL-6 (c) and IL-18 (d) according to the

increase of plasma concentrations of acute phase proteins, such as CRP $[44,9]$. As in this study, the correlation between IL- 6 and abdominal adiposity has been previously documented [18, 21], and chronic elevations of IL- 6 concentration have been associated with both obesity and insulin resistance [32]. IL-6, produced in large scale in adipose tissue macrophages, may have a pivotal role in obesity and insulin resistance, impairing insulin sensitivity by reducing tyrosine phosphorylation and increasing serine phosphorylation of key molecules in the insulin signaling pathway, leading to resistance to its action in target tissues, increasing lipolysis and decreasing glucose uptake in the adipose tissue [15]. Although in this study IL-6 levels were not associated with insulin resistance when measured as HOMA index, subjects with higher IL-6 concentration showed a higher

distribution of TyG index into tertiles. Data are expressed as median (interquartile range)

TyG index. In this sense, Vasques et al. [40] suggested that the TyG index was a better predictor of insulin resistance than the HOMA-IR.

Regarding inflammatory markers, plasma concentration of IL- 6 was a predictor of CRP, as has been reported in the scientific literature [43], even after adjustment for factors related to the lifestyle. Other studies have suggested that CRP concentrations were independently associated to insulin resistance [31], even in a healthy population [43], strengthening the relationship between IL- 6 concentrations and insulin resistance. However, the predictive power of IL6 in relation to $\mathrm{C} 3$ and total cholesterol was not significant after adjusting for the daily number of cigarettes smoked. In fact, it has been reported that smoking is associated with elevated levels of plasma IL-6 [16], and high concentrations of IL- 6 may be a central mediator of the association between 
Table 3 Multiple linear regression analyses showing the independent contributions of variables of studied domains to the variation of the plasma IL-6 and IL-18 concentrations

\begin{tabular}{|c|c|c|c|}
\hline Variables & B coefficient & $95 \%$ Confidence interval & $P$ value \\
\hline \multicolumn{4}{|l|}{ Plasma IL- 6 as dependent } \\
\hline Age (years) & -0.015 & $(-0.030 ; 0.000)$ & 0.043 \\
\hline $\mathrm{BMI}\left(\mathrm{kg} / \mathrm{m}^{2}\right)$ & 0.025 & $(0.008 ; 0.042)$ & 0.003 \\
\hline Triglycerides (mg/dL) & -0.002 & $(-0.003 ; 0.000)$ & 0.013 \\
\hline Glucose (mg/dL) & 0.006 & $(0.000 ; 0.011)$ & 0.040 \\
\hline C3 complement (g/l) & 0.215 & $(-0.019 ; 0.449)$ & 0.072 \\
\hline $\mathrm{CRP}(\mathrm{mg} / \mathrm{L})$ & 0.118 & $(0.065 ; 0.170)$ & $<0.001$ \\
\hline Cigarette (n/day) & 0.002 & $(-0.006 ; 0.011)$ & 0.610 \\
\hline Physical activity (metabolic equivalents $\mathrm{h} /$ week) & -0.001 & $(-0.002 ; 0.000)$ & $\begin{array}{l}0.157 \\
R^{2}=0.242(P<0.001)\end{array}$ \\
\hline \multicolumn{4}{|l|}{ Plasma IL-18 as dependent } \\
\hline BMI $\left(\mathrm{kg} / \mathrm{m}^{2}\right)$ & -0.032 & $(-0.059 ;-0.005)$ & 0.021 \\
\hline Total cholesterol/HDL & 0.008 & $(-0.101 ; 0.117)$ & 0.879 \\
\hline Triglycerides (mg/dL) & 0.002 & $(-0.001 ; 0.005)$ & 0.113 \\
\hline C3 complement (g/l) & 0.563 & $(0.188 ; 0.938)$ & 0.003 \\
\hline HOMA-IR & 0.119 & $(0.030 ; 0.208)$ & 0.009 \\
\hline Smoking time (years) & 0.038 & $(0.010 ; 0.066)$ & $\begin{array}{l}0.008 \\
R^{2}=0.193(P<0.001)\end{array}$ \\
\hline
\end{tabular}

Domains are adiposity indicator, lipid markers, glucose marker, inflammatory marker and lifestyle features

Adjusted $R^{2}$ and all independent variables included in each model are presented in the table. Non-normally distributed variables were logtransformed prior to inclusion in linear regression

In italics are $p$ values $<0.05$

smoking and cardiovascular risk [26]. On the other hand, IL-6 elicited in exercise has been proposed to have an antiinflammatory effect and to regulate the food intake by the sensitization of insulin and leptin central action [35]. In general, the increase in IL- 6 production in skeletal muscle occurs concomitantly to a decrease in TNF- $\alpha$ secretion, resulting in an anti-inflammatory effect [33]. However, in this case, IL-6 levels were neither related to physical activity nor to TNF- $\alpha$ concentration, suggesting a classical proinflammatory role of IL-6 in relation to obesity.

In this study, although higher plasma concentrations of IL-18 were not associated with increased central adiposity, this cytokine was related with a higher TC:HDL ratio, considered a surrogate of cardiovascular risk. It was also observed that insulin and triglycerides levels, and insulin resistance assessed as HOMA-IR, were influenced by IL-18 levels, even after adjusting for age and lifestyle. These predictions, although statistically significant, seem to have little biologic importance, once IL-18 has a very small influence in the values of metabolic and inflammatory traits.
$\mathrm{IL}-18$ has been previously related to obesity and type 2 diabetes [45], atherosclerosis [12], and MetS [22]. Zorrilla et al. [46] reported that IL-18 modulates food intake, metabolism, and adiposity, suggesting a protective effect of this interleukin in obesity. These data were confirmed by Netea et al. [29] who, using genetically modified mice, observed that the absence of IL-18 induced hyperphagia, hyperglycemia, obesity, and insulin resistance, whereas the administration of recombinant IL-18 improved such metabolic defects. Taken together, these outcomes suggest that elevated levels of IL-18 associated with adiposity may occur due to resistance to the action of this interleukin, such occurs with insulin or leptin [45]. Studies correlating the plasma concentration of IL-18 to individual components of MetS have been previously reported [6], as well as the progressive increase in the levels of IL-18 in relation to the number of MetS components, regardless adjusting for age, gender, BMI, and insulin levels [22]. However, in the present study, IL-18 did not appear to be a good biomarker of MetS components in young healthy subjects as it was not able to detect early changes in metabolic features. 

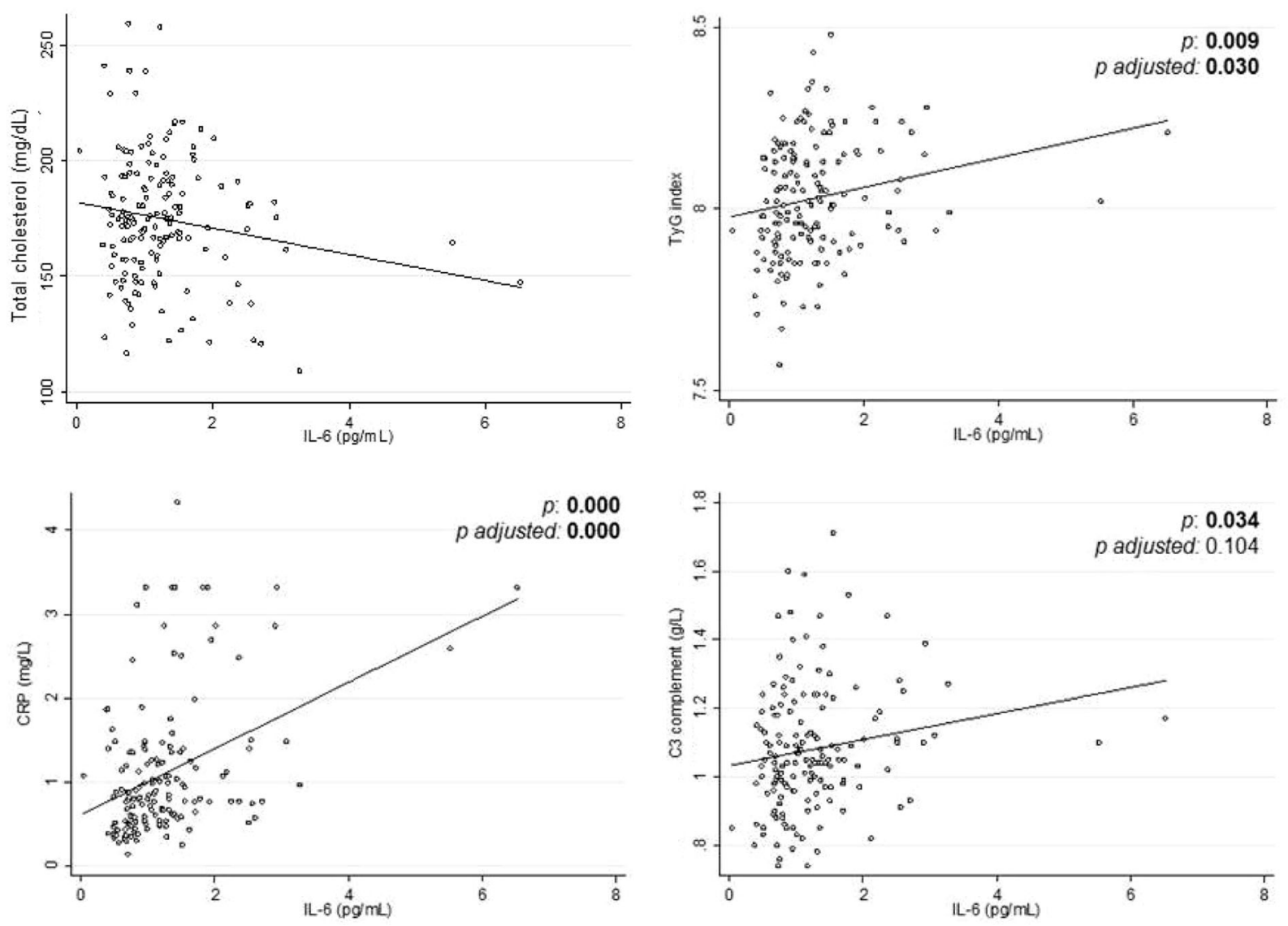

Fig. 2 Multiple linear regression analyses with IL-6 concentrations (pg/mL) as a predictor of total cholesterol, TyG index, CRP, and C3 complement adjusted by number of cigarettes smoked per day $(n=153)$

Regarding lipid metabolism, Blankenberg et al. [3] reported a positive correlation between IL-18 and serum triglycerides and a negative correlation with HDL. Although we have not observed a negative correlation between IL-18 and HDL, the higher TC:HDL ratio among individuals with higher circulating levels of IL18 suggests a comparable cardiometabolic risk. As observed in our results, Blankenberg et al. [3] also found that smoking interfered in the concentrations of IL-6, but not in those of IL-18 [3].

In this study, differences in cytokine concentrations between genders were not observed. Men had a trend to higher levels of IL-6 but not significant. This result was similar to other results obtained in previous reports [5]. However, concerning IL-18, we have not observed differences between both genders. Although most of the studies have observed higher levels of IL-18 in men [30], Chen et al. [7] found similar levels of IL-18 between healthy men and women, but higher levels in men with MetS.
It is known that some components of the diet [19] and physical activity [24] can influence the inflammatory status. However, these relationships were not observed in the current study. The exception was the lowest phosphorus intake among individuals with higher levels of IL-6.

This study has some limitations, since relationships of cause and effect between the associations cannot be assumed due to the cross-sectional nature of the study. The sample composition (only young and apparently healthy volunteers, not including individuals with MetS diagnoses) does not allow the evaluation of potential associations of IL- 6 and IL-18 with the disease. In fact, this experimental design was conducted in order to analyze these inflammatory mediators as early biomarkers of metabolic features/disorders even in young healthy subjects. A future research with this same population might help to clarify if these subjects with trend to insulin resistance really developed this disturbance.

In conclusion, the results of this study suggest that IL-6 concentrations may be linked to adiposity traits and 
increased risk of insulin resistance, measured by TyG index, in young healthy subjects. Thus, IL-6 can be an early risk factor for the development of chronic diseases. In any case, such effects may be influenced by smoking habit, once the number of cigarette smoked per day was associated to higher concentrations of IL-6. Moreover, IL-6 seems to be a better early biomarker of metabolic traits in young healthy subjects than IL-18.

Acknowledgments We wish to thank the physician Blanca E. Martínez de Morentín, the nurse Salomé Pérez, and the technician Verónica Ciaurriz. This work was supported by Linea Especial about Nutrition, Obesity and Health (University of Navarra LE/97) and CIBERobn. We also thanks to Capes for a PhD scholarship awarded to JCC Carraro. J Bressan and HHM Hermsdorff are CNPq and FUNARBE-UFV fellows, respectively.

Conflict of interest The authors declare that they have no competing interests.

Author contributions JCCC analyzed and wrote the manuscript. HHMH contributed in the design, field work, data collection, and analysis. BP contributed in the design, field work, and data collection. MAZ, FIM, and JB contributed in the design and analysis. JAM contributed in the general coordination, design, and financial management. All authors assisted in editing the manuscript as well as reading and approving the final manuscript.

\section{References}

1. Ahmad R, Al-Mass A, Al-Ghawas D et al (2013) Interaction of osteopontin with IL-18 in obese individuals: implications for insulin resistance. PLoS ONE 8(5):e63944

2. Blackburn P, Després J-P, Lamarche B et al (2006) Postprandial variations of plasma inflammatory markers in abdominally obese men. Obesity 14(10):1747-1754

3. Blankenberg S, Luc G, Ducimetière P et al (2003) Interleukin18 and the risk of coronary heart disease in European men: the prospective epidemiological study of myocardial infarction (PRIME). Circulation 108(20):2453-2459

4. Bondia-Pons I, Ryan L, Martinez JA (2012) Oxidative stress and inflammation interactions in human obesity. J Physiol Biochem 68(4):701-711

5. Breyer MK, Rutten EPA, Vernooy JHJ, Spruit MA, Dentener MA, van der Kallen C, vanGreevenbroek MMJ, Wouters EFM (2011) Gender differences in the adipose secretome system in chronic obstructive pulmonary disease (COPD): a pivotal role of leptin. Respir Med 105:1046-1053

6. Bruun J, Stallknecht B, Helge J, Richelsen B (2007) Interleukin-18 in plasma and adipose tissue: effects of obesity, insulin resistance, and weight loss. Eur J Endocrinol 157:465471
7. Chen YC, Chen SD, Miao L, Liu ZG, Li W, Zhao ZX, Sun XJ, Jiang GX, Cheng Q (2012) Serum levels of interleukin (IL)18, IL-23 and IL-17 in Chinese patients with multiple sclerosis. J Neuroimmunol 243(1-2):56-60

8. Ching PL, Willett WC, Rimm EB et al (1996) Activity level and risk of overweight in male health professionals. Am J Public Health 86(1):25-30

9. Diehl S, Rincón M (2002) The two faces of IL-6 on Th1/Th2 differentiation. Mol Immunol 39(9):531-536

10. Dinarello CA (1999) IL-18: A TH1 -inducing, proinflammatory cytokine and new member of the IL-1 family. J Allergy Clin Immunol 103(1):11-24

11. Fantuzzi G (2005) Adipose tissue, adipokines, and inflammation. J Allergy Clin Immunol 115(5):911-919

12. Gerdes N, Sukhova GK, Libby P et al (2002) Expression of interleukin (IL)-18 and functional IL-18 receptor on human vascular endothelial cells, smooth muscle cells, and macrophages: implications for atherogenesis. J Exp Med 195:245-257

13. Goyenechea E, Parra D, Martínez JA (2007) Impact of interleukin 6-174G $>$ C polymorphism on obesity-related metabolic disorders in people with excess in body weight. Metabolism 56(12):1643-1648

14. Gülçubuk A, Haktanir D, Cakiris A et al (2014) The effects of resveratrol on tissue injury, oxidative damage, and proinflammatory cytokines in an experimental model of acute pancreatitis. J Physiol Biochem 70(2):397-406

15. Gustafson B, Hammarstedt A, Andersson CX et al (2007) Inflamed adipose tissue: a culprit underlying the metabolic syndrome and atherosclerosis. Arterioscler Thromb Vasc Biol 27(11):2276-2283

16. Helmersson J, Larsson A, Vessby B, Basu S (2005) Active smoking and a history of smoking are associated with enhanced prostaglandin F2 $\alpha$, interleukin- 6 and F2-isoprostane formation in elderly men. Atherosclerosis 181(1):201-207

17. Hermsdorff H, Zulet MA, Abete I, Martínez JA (2011) A legume-based hypocaloric diet reduces proinflammatory status and improves metabolic features in overweight/obese subjects. Eur J Nutr 50(1):61-69

18. Hermsdorff H, Zulet MA, Puchau B, Martínez JA (2011) Central adiposity rather than total adiposity measurements are specifically involved in the inflammatory status from healthy young adults. Inflammation 34(3):161-170

19. Hermsdorff HH, Zulet MA, Martínez JA (2011) The implication of unknown bioactive compounds and cooking techniques in relations between the variety in fruit and vegetable intake and inflammation. Am J Clin Nutr 93(6):1384

20. Hermsdorff HHM, Puchau B, Bressan J, Martínez JA (2009) Association of retinol-binding protein-4 with dietary selenium intake and other lifestyle features in young healthy women. Nutrition 25(4):392-399

21. Hermsdorff HHM, Puchau B, Bressan J, Martínez JA (2010) Association of body Fat distribution with proinflammatory gene expression in peripheral blood mononuclear cells from young adult subjects. OMICS: J Integr Biol 14(3):297-307

22. Hung J, McQuillan BM, Chapman CML (2005) Elevated interleukin-18 levels are associated with the metabolic syndrome independent of obesity and insulin resistance. Arterioscler Thromb Vasc Biol 25(6):1268-1273

23. Kim T, Choi S, Ha E et al (2013) IL-6 induction of TLR-4 gene expression via STAT3 has an effect on insulin resistance in human skeletal muscle. Acta Diabetol 50(2):189-200 
24. Lavie CJ, Church TS, Milani RV, Earnest CP (2011) Impact of physical activity, cardiorespiratory fitness, and exercise training on markers of inflammation. J Cardiopulm Rehabil Prev 31(3):137-145

25. Matthews DR, Hosker JP, Rudenski AS, Nayloret BA et al (1985) Homeostasis model assessment: insulin resistance and beta-cell function from fasting plasma glucose and insulin concentrations in man. Diabetologia 28(7):412-9

26. McCarty MF (1999) Interleukin-6 as a central mediator of cardiovascular risk associated with chronic inflammation, smoking, diabetes, and visceral obesity: down-regulation with essential fatty acids, athanol and pentoxifylline. Med Hypotheses 52(5):465-477

27. Medzhitov R (2008) Origin and physiological roles of inflammation. Nature 454(7203):428-435

28. Moreno-Aliaga M, Campión J, Milagro FI et al (2005) Adiposity and proinflammatory state: the chicken or the egg. Adipocytes 1:1-16

29. Netea MG, Joosten LAB, Lewis E et al (2006) Deficiency of interleukin-18 in mice leads to hyperphagia, obesity and insulin resistance. Nat Med 12(6):650-656

30. Opstad TB, Pettersen AA, Arnesen H, Seljeflot I (2011) Circulating levels of IL-18 are significantly influenced by the IL- $18+183 \mathrm{~A} / \mathrm{g}$ polymorphism in coronary artery disease patients with diabetes type 2 and the metabolic syndrome: an observational study. Cardiovasc Diabetol 10:110

31. Pannacciulli N, Cantatore FP, Minenna A et al (2001) Creactive protein is independently associated with total body fat, central fat, and insulin resistance in adult women. International journal of obesity and related metabolic disorders. Int J Obes Relat Metab Disord 25(10):1416-1420

32. Pedersen M, Bruunsgaard $\mathrm{H}$, Weis $\mathrm{N}$ et al (2003) Circulating levels of TNF-alpha and IL-6-relation to truncal fat mass and muscle mass in healthy elderly individuals and in patients with type-2 diabetes. Mech Ageing Dev 124(4):495-502

33. Petersen AMW, Pedersen BK (2006) The role of il-6 in mediating the anti-inflammatory effects of exercise. J Physiol Pharmacol 57(10):43-51

34. Quintero P, Milagro FI, Campion J, Martínez JA (2010) Impact of oxygen availability on body weight management. Med Hypotheses 74(5):901-907

35. Ropelle ER, Flores MB, Cintra DE et al (2010) IL-6 and IL-10 anti-inflammatory activity links exercise to hypothalamic insulin and leptin sensitivity through IKK $\beta$ and ER stress inhibition. PLoS Biol 8(8):e1000465
36. Safavi SM, Ziaei R, Marac MR (2012) Association of serum ceruloplasmin level with obesity: some components of metabolic syndrome and high-sensitive C-reactive protein in Iran. J Obes 2012:951093

37. Simental-Mendía L, Rodríguez-Morán M, GuerreroRomero F (2008) The product of fasting glucose and triglycerides as surrogate for identifying insulin resistance in apparently healthy subjects. Metab Syndr Relat Disord 6:299-304

38. Thaler JP, Schwartz MW (2010) Minireview: inflammation and obesity pathogenesis: the hypothalamus heats up. Endocrinology 151(9):4109-4115

39. Vachharajani V, Granger DN (2009) Adipose tissue: a motor for the inflammation associated with obesity. IUBMB Life 61(4):424-430

40. Vasques ACJ, Novaes FS, de Oliveira MS et al (2011) TyG index performs better than HOMA in a Brazilian population: a hyperglycemic clamp validated study. Diabetes Res Clin Pract 93(3): e98-e100

41. Wang B, Li Q, Jiang Y et al (2011) Serum complement C3 has a stronger association with insulin resistance than high sensitive C-reactive protein in non-diabetic Chinese. Inflamm Res 60(1):63-68

42. Whitworth JA, Chalmers J (2004) World health organisationinternational society of hypertension (WHO/ISH) hypertension guidelines. Clin Exp Hypertens 26(7-8):747-52

43. Yudkin JS, Stehouwer CDA, Emeis JJ, Coppack SW (1999) C-reactive protein in healthy subjects: associations with obesity, insulin resistance, and endothelial dysfunction: a potential role for cytokines originating from adipose tissue? Arterioscler Thromb Vasc Biol 19(4):972-978

44. Yudkin JS, Kumari M, Humphries SE, Mohamed-Ali V (2000) Inflammation, obesity, stress and coronary heart disease: is interleukin-6 the link? Atherosclerosis 148(2):209214

45. Zilverschoon GRC, Tack CJ, Joosten LAB et al (2008) Interleukin-18 resistance in patients with obesity and type 2 diabetes mellitus. Int J Obes 32(9):1407-1414

46. Zorrilla EP, Sanchez-Alavez M, Sugama S et al (2007) Interleukin-18 controls energy homeostasis by suppressing appetite and feed efficiency. Proc Natl Acad Sci U S A 104(26):11097-11102

47. Zulet MA, Puchau B, Navarro C et al (2007) Biomarcadores del estado inflamatorio: nexo de unión con la obesidad y complicaciones asociadas. Nutr Hosp 22(5):511-527 